\title{
ASCERTAINING THE SUITABILITY OF WRITING SYLLABUS SPECIFICATIONS TO THE CEFR: SUBJECT MATTER EXPERTS' PERSPECTIVES
}

\author{
Nurul Farehah Mohamad Uri*1 \\ Mohd Sallehhudin Abd Aziz ${ }^{2}$ \\ ${ }^{1}$ Universiti Kuala Lumpur British Malaysian Institute \\ ${ }^{2}$ Universiti Kebangsaan Malaysia \\ ${ }^{1}$ nfarehah@unikl.edu.my \\ 2salleh@ukm.edu.my
}

Manuscript received 10 February 2020

Manuscript accepted 18 June 2020

*Corresponding author

https://doi.org/10.33736/ils.2347.2020

\begin{abstract}
The Implementation of CEFR in Malaysia is currently at the second stage whereby the classroom usage of the new CEFR-aligned syllabus and assessment has taken place since 2017 at all stages except for Form 5. Previous studies on CEFR in Malaysia have focused more on teachers' views and their readiness in accepting the new changes. However, this study focusses more on ascertaining the suitability of the writing syllabus specifications against the CEFR writing scale to find out if the CEFR levels of writing syllabus specifications recommended by the teachers match the CEFR level set by the Ministry of Education, Malaysia. A total of 331 secondary school teachers were asked to respond to the writing syllabus checklist and the Winstep SPSS was used for data analysis. Findings have shown that productive skills of the writing syllabus specifications were found not to be aligned to the target CEFR level set by the Ministry. In conclusion, adjustment and alignment processes should be made accordingly to align and match the non-CEFR aligned English syllabus to the CEFR global scale instead of eradicating it.
\end{abstract}

Keywords: CEFR writing descriptors; English syllabus; suitability; teachers' judgements

\section{Introduction}

The Common European Framework of Reference (CEFR) is a universal and dynamic framework developed by the Council of Europe to be used as a reference by language learners, academics, textbooks developers and policymakers. The framework has been widely used across countries in Asia and Europe because of its

Ascertaining the Suitability of Writing Syllabus Specifications to the CEFR: Subject Matter Experts' Perspectives 
flexibility and adaptability to cater to different needs and contexts of language users (Council of Europe, 2001). CEFR comes with a six global scale descriptors and individual scale descriptors of the four language skills: reading, writing, speaking and listening.

In the latest version of the framework which was improved and published in 2018 by the Council of Europe, several new scales were added such as reading as leisure activity, using telecommunications and sustained monologue: giving and exchanging information. Level pre-A1 was added and phonology scale was redeveloped focusing on sound articulation and prosodic features (Council of Europe, 2018). The scale comprises three main descriptor scales: reception, interaction and production. Table 1 illustrates the writing scale with the descriptors.

Table 1

CEFR writing descriptors (Council of Europe, 2018)

\begin{tabular}{cl}
\hline CEFR level & \multicolumn{1}{c}{ Writing Descriptors } \\
\hline C2 & $\begin{array}{l}\text { I can write clear, smoothly flowing text in an appropriate style. I can } \\
\text { write complex letters, reports or articles, which present a case with } \\
\text { an effective logical structure, which helps the recipient to notice and } \\
\text { remember significant points. I can write summaries and reviews of } \\
\text { professional or literary works. }\end{array}$ \\
\hline C1 & $\begin{array}{l}\text { I can express myself in clear, well-structured text, expressing points of } \\
\text { view at some length. I can write detailed expositions of complex } \\
\text { subjects in an essay or a report, underlining what I consider to be the } \\
\text { salient issues. I can write different kinds of texts in a style appropriate } \\
\text { to the reader in mind. }\end{array}$ \\
\hline B2 & $\begin{array}{l}\text { I can write clear, detailed text on a wide range of subjects related to } \\
\text { my interests. I can write an essay or report, passing on information or } \\
\text { giving reasons in support of or against a particular point of view. }\end{array}$ \\
\hline B1 & $\begin{array}{l}\text { I can write straightforward connected text on topics, which are } \\
\text { familiar, or of personal interest. }\end{array}$ \\
\hline A2 & $\begin{array}{l}\text { I can write a series of simple phrases and sentences linked with } \\
\text { simple connectors like "and", "but" and "because". }\end{array}$ \\
\hline A1 & I can write simple isolated phrases and sentences. \\
\hline
\end{tabular}

\section{Educational Reform: CEFR in Malaysia}

Malaysia is among the countries in South East Asia which have adopted the CEFR framework into the education system. The implementation process is not conducted in isolation as it involves educational reform at the national level which would lead to major changes. The major changes include evaluation of the English syllabus, teacher training, development of CEFR descriptors, determining the suitability of the CEFR level for each of the educational stages and alignment of the curricula as well as assessment to the CEFR (Nurul Farehah Mohamad Uri \& Mohd Sallehhudin Abd Aziz, 2019).

Ascertaining the Suitability of Writing Syllabus Specifications to the CEFR: Subject Matter Experts' Perspectives 
The educational reform is divided into three phases which started in 2013 and will officially end in 2025. As shown in Table 2, the first two years of the educational reform focused on evaluation of the current education system and curricula. Teachers were also sent for various trainings and suitable CEFR descriptors were developed and established. In stage 2, the reform continues with the alignment of English syllabus and assessment to the CEFR as well as selection of CEFR-aligned textbooks. The final stage which will commence in 2021 is known as the review stage whereby the developed CEFR descriptors will be reviewed and revised, and both CEFR-aligned textbooks and the usage of CEFR in the classroom will be evaluated. This is also the stage in which the CEFR-M (the Malaysian version of the descriptor) will be developed by local experts.

Table 2

Educational reform plan

\begin{tabular}{lll}
\hline \multicolumn{1}{c}{ Stage 1 (2013-2015) } & \multicolumn{1}{c}{ Stage 2 (2016-2020) } & \multicolumn{1}{c}{ Stage 3 (2021 - 2025) } \\
\hline $\begin{array}{l}\text { Strengthening the current } \\
\text { education system and } \\
\text { curricula. }\end{array}$ & $\begin{array}{l}\text { Introduce structural } \\
\text { changes. }\end{array}$ & $\begin{array}{l}\text { The developed CEFR } \\
\text { descriptors will be reviewed } \\
\text { and revised. }\end{array}$ \\
$\begin{array}{l}\text { English teachers Malaysia are } \\
\text { sent for various trainings. }\end{array}$ & $\begin{array}{l}\text { Suitable CEFR descriptors are } \\
\text { developed for each } \\
\text { educational level. }\end{array}$ & $\begin{array}{l}\text { Development of CEFR-M by } \\
\text { CEFR special task force. }\end{array}$ \\
$\begin{array}{l}\text { CEFR descriptors are } \\
\text { developed, educational } \\
\text { staged targets are set, and } \\
\text { capacity is built. }\end{array}$ & $\begin{array}{l}\text { The process of aligning } \\
\text { as well as School Based }\end{array}$ & $\begin{array}{l}\text { Evaluation of the selected } \\
\text { textbooks and support } \\
\text { materials. }\end{array}$ \\
& $\begin{array}{l}\text { CEFR. } \\
\text { International CEFR-aligned } \\
\text { textbooks and support } \\
\text { materials were selected. }\end{array}$ & $\begin{array}{l}\text { Evaluate teachers' use of the } \\
\text { CEFR in teaching and } \\
\text { learning process as well as } \\
\text { assessment practices. }\end{array}$ \\
\hline
\end{tabular}

\section{Linking writing to the CEFR}

Studies related to the use of CEFR in the classroom, the effectiveness of the framework to language learners, academic views and acceptance of CEFR implementation are among the areas of research conducted that are linked to the framework. Linking writing skills or assessment to the CEFR has also gained special interest among academics and researchers. In one of the public universities in Malaysia, an attempt was made to align their existing in-house developed test known as English Proficiency Test (EPT) focusing only on the writing component to the CEFR. The writing scripts were graded according to the CEFR writing scales instead of their own scoring rubrics. Comparison between the scripts graded using CEFR and non-CEFR scale was made. It was found that the EPT band correlates positively and hierarchically to the CEFR rating scale with an acceptable one band difference (Engku Haliza, Isarji, Khairiah, Faridah \& Ainon, 2017). 
A similar study was also conducted in China using the Test for English Majors (TEM) writing scripts with the aim of finding out the extent to which CEFR descriptors are adaptable in describing TEM candidates' writing proficiency. The results indicate that CEFR writing descriptors can be used to describe TEM candidates' writing ability with minimal alteration made to the original level of descriptors (Zhou \& Zhang, 2017). Zheng, Zhang, and Yan's (2016) study showed that the Chinese teachers believed that the CEFR and CET evaluation standards differ in aims and functions, and focused on different aspects of students' ability. Previous studies by Engku Haliza et al. (2017), Zhou and Zhang (2017) and Zheng, Zhang, and Yan (2016) only focused on grading written assessment against CEFR. Determining the suitability of the writing syllabus to the CEFR in the alignment process is an area which has yet to be discovered. This is due to the fact that the adoption of CEFR involves a total change of the syllabus, hence there is no necessity to find out the suitability of the current writing syllabus against the CEFR global scale.

In order to implement CEFR in the education system, the alignment of the English subject to the CEFR would include changes to both the syllabus and assessment. Therefore, it would be vital to also find out if the current English syllabus is suitable and can be mapped against the CEFR writing scale. Doing so would help policymakers to decide whether the alignment process should involve a total revamp of the syllabus or it would be sufficient to just adapt where relevant, which means retaining some parts of the writing syllabus which are found suitable and can be used with the CEFR scale. According to O'Dwyer (2014), the alignment of the syllabus to the CEFR does not directly mean major changes which involve replacement of the syllabus component since it would be sufficient to evaluate the current syllabus with necessary alignment. Therefore, it would be crucial to conduct a study to find out if the current writing syllabus of Form 5 English should be totally revamped or adapted in the process of aligning it to the CEFR writing descriptors. Specifically, the objectives of this study are to ascertain the suitability of writing syllabus specifications against CEFR writing scale and to find out if the CEFR levels of writing syllabus specifications recommended by the teachers match the CEFR level set by the Ministry of Education as stipulated in the Education Blueprint 2015-2025.

\section{Methodology}

A total of 331 secondary school teachers around Putrajaya, Kuala Lumpur and Selangor took part in this study since they were the subject matter experts. The teachers involved in this study have the minimum of a degree in English education with 10 to 20 years of teaching experience and they were also teachers with master's degree qualifications. English teachers who took part in this study were chosen based on the recommendation of English head of panels. All the teachers were familiar with CEFR and have at least attended CEFR familiarisation workshop organised by the Ministry of Education. 
The writing syllabus checklist and CEFR writing scale descriptors were the main research instruments used in the study. Both instruments were administered by hand from school to school which took about a month. The CEFR writing scale descriptors were appended as a reference to the teachers. In order to ensure the reliability of the checklist, a pilot test was conducted and two statistical tools (SPSS 23 and Winstep) were used to gather the reliability data. Table 3 shows that the value of Cronbach's Alpha is .951, and reliability items for students and teachers are at .74 and .93 respectively. The high values of reliability readings for the syllabus checklist mean that the research instrument did not require any amendments since an overall alpha value of .70 and more is considered good and acceptable (Taber, 2018).

Table 3

Reliability statistics of the writing syllabus checklist

\begin{tabular}{cccc}
\hline N of items & $\begin{array}{c}\text { Cronbach's } \\
\text { Alpha }\end{array}$ & $\begin{array}{c}\text { Reliability items } \\
\text { (students) }\end{array}$ & $\begin{array}{c}\text { Reliability } \\
\text { (teachers) }\end{array}$ \\
\hline 30 & .951 & .74 & .93 \\
\hline
\end{tabular}

The data were also analysed using Winstep to determine the suitability of the writing syllabus specifications to the CEFR level based on the values of logit, S.E and Infit Mean Square (MnSq). Winstep was chosen for the data analysis because Winstep offers detailed results which include the logit value, S.E value and Infit mnsq value which is suitable in finding the suitability of an item. Table 4 shows the interpretation values of Infit mean square (MnSq) which are grouped into three. Items which fall between the values of 0.6 and 1.4 are considered as suitable items with good values. Items which have the value of more than 1.4 are classified as difficult and confusing items, whereas items which are considered as too easy would have the infit mnsq values of less than 0.6 .

Table 4

Infit mean square (MnSq) interpretation of values

\begin{tabular}{cc}
\hline Suggested value range & Interpretations of value \\
\hline $0.6-1.4$ & Suitable item \\
$1.4>$ & Difficult \& confusing item \\
$<0.6$ & Item is too easy \\
\hline
\end{tabular}




\section{Results}

\section{Suitable and Relevant Writing Syllabus Specifications against CEFR Scale}

The detail logit, S.E and Infit MnSq values of thirty writing syllabus specifications which determine the suitability and relevance of the syllabus specifications to be used against CEFR scale are presented in the writing syllabus specifications measurement report.

Table 5

Writing syllabus specifications measurement report

\begin{tabular}{|c|c|c|c|}
\hline $\begin{array}{c}\text { Syllabus } \\
\text { specifications }\end{array}$ & Logit & S.E & Infit MnSq \\
\hline W1 & 1.14 & 21 & 1.52 \\
\hline W22 & .83 & 21 & 2.69 \\
\hline W2 & .70 & 21 & .81 \\
\hline W8 & .48 & 21 & .60 \\
\hline W21 & .35 & 21 & 1.44 \\
\hline W23 & .30 & 21 & .95 \\
\hline W6 & .26 & 21 & 1.32 \\
\hline W12 & .17 & 21 & 1.00 \\
\hline W11 & .13 & 21 & .76 \\
\hline W4 & .08 & 21 & 1.12 \\
\hline W9 & .08 & 21 & .76 \\
\hline W19 & -.01 & 21 & 1.08 \\
\hline W3 & -.06 & 21 & .10 \\
\hline W5 & -.06 & 21 & 1.76 \\
\hline W24 & -.10 & 21 & .89 \\
\hline W20 & -.19 & 22 & 1.36 \\
\hline W14 & -.24 & 22 & .75 \\
\hline W18 & -.29 & 22 & .63 \\
\hline W25 & -.29 & 22 & .56 \\
\hline W10 & -.33 & 22 & .48 \\
\hline W7 & -.43 & 22 & 1.21 \\
\hline W13 & -.53 & 22 & .42 \\
\hline W15 & -.58 & 22 & .63 \\
\hline W16 & -.68 & 23 & .94 \\
\hline W17 & -.73 & 23 & .87 \\
\hline W29 & .00 & 24 & 2.47 \\
\hline W27 & -.12 & 24 & .80 \\
\hline W28 & -.30 & 25 & 1.02 \\
\hline W26 & -.42 & 25 & .67 \\
\hline W30 & -.48 & 25 & .96 \\
\hline
\end{tabular}

Ascertaining the Suitability of Writing Syllabus Specifications to the CEFR: Subject Matter Experts' Perspectives 
Table 5 presents the results of the writing items measurement report for writing skills syllabus specifications and it is significant that the results can be grouped into six categories based on the S.E values. The first group is syllabus specifications with positive logit values and S.E value of 21 . The second group is also a group with S.E value of 21 but the syllabus specifications have negative logit values. The third group is syllabus specification with negative logit values and S.E value of 22 . The fourth group is syllabus specifications with S.E value of 23 and negative logit values. The fifth group is items with negative logit values and S.E value of 24 , and the last group is syllabus specifications with S.E value of 25 . It is important to highlight the different categories of syllabus specifications based on logit values and S.E values as it carries different interpretations of the entire results.

It can be seen from Table 5 that the S.E values for writing items are 21, 22, 23,24 and 25 . There are 15 syllabus specifications with S. E value of 21 and these represent half of the syllabus specifications in the list. The smallest S.E value is 21 which indicates that the syllabus specifications are among the most difficult as compared to other syllabus specifications with S.E values of 22, 23, 24 and 25. Syllabus specifications W1 (Keeping a record of events) and W22 (Describing the setting of a story) are the syllabus specifications at the top of the list with logit values of 1.14 and .83 each. Syllabus specification W1 is the most difficult specification in the list of writing skills since it is the first syllabus specification in the list. Labelled as the most difficult syllabus specification, item W1 is supported by the S.E value of 21.

Syllabus specification W22 is the second most difficult specification after W1 which also shares the same S.E value of 21 . Hence, there is no doubt that both syllabus specifications $\mathrm{W} 1$ and $\mathrm{W} 22$ are considered as the most difficult syllabus specifications based on the combination of logit value and S.E value. Nevertheless, the most difficult syllabus specifications such as W1 and W2 do not necessarily mean that these syllabus specifications are suitable because the infit mnsq values of syllabus specifications W1 and W22 show otherwise. Syllabus specification W1 has the infit mnsq value of 1.52 and the infit mnsq value of W22 is 2.69. These syllabus specifications have the value of infit mnsq more than 1.4 which makes it not suitable and should be removed from the list because it is considered too difficult. This implies that the teachers are in agreement that keeping a record of events and describing the setting of a story are no longer suitable to be included in Form 5 English syllabus.

Under similar S.E value of 21 , there are another nine syllabus specifications with positive logit values and these logit values are the factors which determine the different level of difficulty of these syllabus specifications. The nine syllabus specifications which are still considered difficult but less difficult compared to syllabus specifications $W 1$ and W22 are W2 (Making enquiries after reading the adverts column in the newspaper/yellow pages and identifying a number of similar services and products) with logit value of .70, W8 (Taking notes of the text heard) with the logit value of .48, W21 (Writing a simple speech on a particular topic) with the logit value of .35, W23 (Narrating the sequence of events) with the logit value of .30 . 
This is followed by syllabus specifications W6 (Expressing satisfaction and offering thanks about the service or product orally and in writing) with the logit value of .26, W12 (Listing important details) with the value of .17, W11 (Making notes and outlines) with the logit value of .13, W4 (Confirming the service/ product and placing an order for it orally and in writing) with the logit value of .08 and W9 (Presenting information in the form of tables, graphs and charts) with the same logit value of .08 . Another similarity between these syllabus specifications are the value of infit mnsq which fall within the suitable range of not less than 0.6 and not more than 1.4 except for syllabus specification W21 since this is the only syllabus specification with infit mnsq value of 1.44 , thus making syllabus specification W21 not suitable and cannot be retained. The infit mnsq values of the remaining eight syllabus specifications are .81 (W2), .60 (W8), .95 (W23), 1.32 (W6), 1.00 (W12), .76 (W11), 1.12 (W4) and .76 (W9) making them suitable and can be retained in the English syllabus.

Apart from the 11 syllabus specifications with positive logit values and S.E value of 21 , there are also four more syllabus specifications with the same S.E value of 21 but the difference lies in the negative logit values of these four syllabus specifications. These four syllabus specifications do have the S.E value of 21 but they cannot be considered difficult like the previous 11 syllabus specifications because the negative logit values of these four syllabus specifications make it less difficult than syllabus specifications W1 - W9. The four syllabus specifications with negative logit values and S.E value of 21 are W19 (Writing reports on specific topics), W3 (Comparing and contrasting the information obtained and deciding on a choice), W5 (Responding to problem page letters in the newspaper or in popular magazines by first discussing them and then writing letters to the editor) and W24 (Describing characters and writing a paragraph or two about them) with the logit values of -.01, $.06,-.06$ and -.10 each. These syllabus specifications are considered difficult but it does not mean syllabus specifications W19, W3, W5 and W24 are not suitable because it is found that W19 and W24 are suitable based on the infit mnsq of 1.08 (W19) and .89 (W24).

The values of infit mnsq for these syllabus specifications are within the suitable range of $\langle 0.6-1.4\rangle$. However, only syllabus specifications W19 and W24 are suitable and can be retained because the other two syllabus specifications W3 and $\mathrm{W} 5$ are found not suitable with the infit mnsq values of lower than 0.6 and also more than 1.4. Syllabus specification W3 only has the value of .10 which is lower than 0.6 whereas syllabus specifications $W 5$ has the value of 1.76 which is more than 1.4. Therefore, it is agreed by the teachers that comparing and contrasting the information obtained and deciding on a choice and responding to problem page letters in the newspaper or in popular magazines by first discussing them and then writing letters to the editor are no longer applicable in the teaching of writing skills to Form 5 students.

The value of S.E gets bigger to 22 as the list goes down and there are eight syllabus specifications which fall under the S.E value of 22 which are syllabus specifications W20 to W15. Since S.E value of 22 is ranged in the middle of the table, these eight syllabus specifications can be considered as items with moderate difficulty level. The negative logit values also mean that these syllabus specifications 
are easier compared to syllabus specifications with positive logit values. Hence, the syllabus specifications with moderate difficulty are W20 (Writing articles on specific topics) with the logit values of -.19, W14 (Summarising ideas in a text) with the logit value of -.24 , W18 (Comparing and contrasting data collected from graphs, tables, charts and diagrams) with the logit value of -.29, W25 (Making predictions as to what might happen next) with the similar logit value of -.29 , W10 (Responding to questions and comments orally and in writing) with the logit value of -.33, W7 (Responding to a complimentary letter expressing satisfaction and thanking the writer orally and in writing) with the logit value of -.43, W13 (Expanding notes and outlines) with the logit value of -.53 and W15 (Identifying cause and effect) with the logit value of -.58 .

These are the same eight syllabus specifications which have negative logit value and S.E value of 21 only but five out of eight syllabus specifications have good values of infit mnsq which are in the range of $0.6-1.4$ and only three syllabus specifications with the infit mnsq value of less than 0.6 . The syllabus specifications which are suitable based on the values of infit mnsq are W20 (1.36), W14 (.75), W18 (.63), W7 (1.21) and W15 (.63) whereas the other three syllabus specifications which are not suitable due to a low value of infit mnsq are W25 (.56), W10 (.48) and W13 (.42). This indicates that only five of these moderate levels of difficulty syllabus specifications that are suitable and shall be retained in the list for teachers to use in teaching writing skills.

There are also two negative logit value of syllabus specifications with a bigger S.E value of 23, namely, W16 (Making inferences) with the logit value of -.68 and W17 (Drawing conclusions) with the logit value of -.73 . This indication means that syllabus specifications W16 and W17 are the moderately easy items in this scale being at the middle of the list with negative logit values. It is also supported with the biggest value of standard error (S.E) for easy items. Not only that, the acceptable infit mnsq values of .94 (W16) and .87 (W17) also indicate that these two syllabus specifications are suitable despite being the two moderately easy syllabus specifications in the list. Henceforth, these syllabus specifications shall be retained to represent the moderately easy type of syllabus specifications.

The S.E value gets bigger as the list goes down to indicate that syllabus specifications for writing skills have quite a number of easy items. There are two easy category items which are represented by S.E value of 24 . One of the syllabus specifications, item W29 (Presenting the text in another genre) has a positive logit value of .00 whereas item W27 (Discussing the theme and message of stories and poems) has a negative logit value of -.12. The logit values and S.E values of both items W29 and W27 pointed out that these items can be categorised as easy items. However, only item W27 is suitable and should be retained although it has a negative logit value. This is because item W27 has a suitable infit mnsq value of .80 . On the other hand, item W29 cannot be retained because the infit mnsq value of 2.47 shows that this item is not suitable because it is too difficult and confusing.

Finally, the bottom three items in the list are considered as the easiest items based on the negative logit values and big S.E value of 25. The easiest items are W28 (Giving one's opinion of the poem or story), W26 (Relating events characters and values to one's life) and W30 (Composing simple poems, stories and dialogues) with 
logit values of $-.30,-.42$ and -.48 each. Interestingly, all these syllabus specifications have good infit mnsq values which fall between the suggested values. As a result, items W28, W26 and W30 are found to be suitable yet among the easiest syllabus specifications with the infit mnsq value of 1.02 (W28), .67 (W26) and .96 (W30). All in all, out of 30 syllabus specifications, only 21 syllabus specifications are suitable and shall be retained so that it can be used with the new CEFR aligned Form 5 English syllabus.

\section{CEFR level of writing syllabus specifications recommended by the teachers}

The suitability of the writing syllabus specifications was determined using a statistical tool. Nonetheless, the CEFR level for individual writing syllabus specifications were recommended by the teachers as subject matter experts. The CEFR level of writing syllabus specifications recommended by the teachers were compared to the CEFR target level set by the Ministry of Education. The details of the findings of the 30 writing syllabus specifications are illustrated in Table 6.

Table 6

CEFR level for writing syllabus specifications

\begin{tabular}{cc|cc}
\hline Syllabus specifications & CEFR level & Syllabus specifications & CEFR level \\
\hline W1 & B2 & W16 & C1 \\
W2 & A2 & W17 & C1 \\
W3 & B2 & W18 & C1 \\
W4 & B1 & W19 & B2 \\
W5 & C1 & W20 & B2 \\
W6 & B2 & W21 & B2 \\
W7 & B2 & W22 & B1 \\
W8 & B2 & W23 & C1 \\
W9 & B2 & W24 & B2 \\
W10 & B2 & W25 & C1 \\
W11 & B2 & W26 & C1 \\
W12 & C1 & W27 & B2 \\
W13 & C1 & W28 & C1 \\
W14 & C1 & W29 & C1 \\
W15 & C1 & W30 & C1 \\
\hline
\end{tabular}

The findings for recommended CEFR level by the teachers for writing skills syllabus specifications are relatively different from listening and reading skills syllabus specifications because there are more syllabus specifications with CEFR level C1 according to teachers' discretion. Nonetheless, the CEFR levels recommended for writing syllabus specifications by the teachers were not final and not necessarily accurate. Hence, the logit values and S.E values should also be considered in deciding if the suggested CEFR level matches the syllabus specifications accurately. Based on the results of recommended CEFR level in Table 5 , it is found that the teachers recommended CEFR level A2 as the lowest level, CEFR

Ascertaining the Suitability of Writing Syllabus Specifications to the CEFR: Subject Matter Experts' Perspectives 
level $\mathrm{B} 1$ and $\mathrm{B} 2$ for the middle range and the highest is CEFR level $\mathrm{C} 1$. In addition, the CEFR level $\mathrm{C} 1$ is the most recommended level by the teachers with the total of 14 and it is followed by CEFR level B2 with 13 syllabus specifications.

In terms of the suggested CEFR levels, syllabus specifications W1 until W9 have a mixture of CEFR levels of B2, B1, A2 and C1. Syllabus specifications W1, W8, W21, W6, W11 and W9 are placed at CEFR level B2 according to a majority of the teachers and recommended CEFR level for syllabus specifications W22 and W4 are B1. The values of logits and S.E support teachers' recommended CEFR level to these syllabus specifications but CEFR level B2 would be more appropriate for syllabus specification W22 instead of B1 level because this syllabus specification is the second most difficult syllabus specification based on the logit value and S.E value. Other than that, the recommended CEFR level for syllabus specifications W2, W23 and W12 probably did not suit these syllabus specifications.

Syllabus specification W2 is the third most difficult item in the list but the recommended CEFR level is $A 2$ and it does not match the logit and S.E values of this item. A2 level might be too easy for an item considered difficult, so a more appropriate CEFR level for syllabus specification W2 is CEFR level B2. The same goes with syllabus specifications W23 and W12 whereby the CEFR level C1 as suggested by the teachers were found to be too high for these items. Syllabus specifications W23 and W12 appeared at number six and eight in the list which directly mean these syllabus specifications are less difficult than syllabus specifications at first and fifth place. Therefore, CEFR level C1 is not suitable for syllabus specifications W23 and W12; CEFR level B2 would a more suitable level for syllabus specification W23 and CEFR level B1 for syllabus specification W12.

Syllabus specifications W19 - W24 are syllabus specifications with negative logit values although the S.E value of 21 is shared with syllabus specifications W1 W9. This means that syllabus specifications W19 - W24 belong to the moderate level items and so CEFR level B2 and C1 suggested by the teachers might be less accurate and therefore should be replaced with CEFR level B1 because it matches the negative logit values of these syllabus specifications. It is similar with syllabus specifications W20 - W17 because obviously these are among the easy types of syllabus specifications with negative logit values and big value of S.E values making suggested CEFR levels C1 and B2 inappropriate. A better and more a suitable CEFR level which also matches the values of logits and S.E of these syllabus specifications are CEFR level B1 for W20 - W17.

Syllabus specifications W29 and W27 have S.E values of 24, whereas syllabus specifications W28 - W30 have the biggest S.E values of 25 . This means that syllabus specifications W29 - W30 are the easiest because of the S.E values. This is also supported by the negative logit values which also indicate that these syllabus specifications are easy. In contrast, the teachers proposed CEFR level that is unrealistic and too high because it does not match the logit and S.E values of these five syllabus specifications. Only syllabus specification W27 is assigned with CEFR level B2 while W29, W28, W26 and W30 are assigned with CEFR level C1 each. Obviously, CEFR level $\mathrm{C} 1$ is too high and too difficult for syllabus specifications which are judged to be among the easiest out of 30 syllabus specifications for writing skill. CEFR levels A1 or A2 would be more appropriate and suitable for syllabus 
specifications W29 - W30. In conclusion, CEFR levels A1, A2, B1 and B2 are more suitable for writing skill syllabus specifications and the teachers' recommendation shows that they overrated the difficulty level of these syllabus specifications.

\section{Conclusion}

The findings of this study reveal that some aspects of the syllabus are aligned to the target CEFR level set by the Ministry of Education and there were also aspects of the syllabus which did not match the target CEFR level for secondary school level. The productive skills of writing syllabus specifications were found to be not aligned to the target CEFR level set by the Ministry of Education. The CEFR level set for secondary school are at levels B1/ B2.

The writing syllabus specifications were found to be one level higher than the target CEFR level as the syllabus specifications in the writing syllabus were found to be at level $\mathrm{C} 1$. This is probably because writing skills require learners to write using target language which might be challenging for some learners according to the teachers. The challenges include learners' ability to construct error free sentences, to possess rich sources of vocabulary and to engage in specific context related speaking and writing tasks. Hence, the results of this present study corroborate a study on calibrating CEFR against China standard of English vocabulary education when the teachers involved in the study agreed to rank the vocabulary descriptors at CEFR level C1 and showed that writing skills were difficult and should be placed at the highest level of CEFR six levels descriptors (Zhao, Wang, Coniam, \& Xie, 2017). The results of the present study are also in line with Zhou and Zhang's (2017) study that focused on exploring the adaptability of the CEFR in the construction of a writing ability scale for test for English majors which found that descriptors of a relatively high difficulty belong to the academic writing domain. Again, it proves that writing skills are considered the most difficult skill compared to reading, listening and speaking skills.

The summary results of the syllabus specifications for writing skills revealed that the total numbers of syllabus specifications which were found suitable and should be retained were more than syllabus specifications which were suggested to be removed from Form 5 English syllabus. Results of the present study proved that the total syllabus alignment against CEFR global scale is not necessary especially when some parts of the non-CEFR aligned syllabus are found to match the six levels of the CEFR descriptors. This corroborates the findings from a previous study in regards to CEFR alignment which found that procedures in the manual by Council of Europe (2009) recommends for linking examination to CEFR levels did not produce sufficient evidence to demonstrate equivalence between different examinations that target particular CEFR levels (Wu \& Wu, 2012).

In conclusion, adjustment and alignment process could be made accordingly to align and match the non-CEFR aligned English syllabus to CEFR global scale instead of abolishing it. Findings from the open-ended items also highlighted the reasons that these syllabus specifications should be retained because it is believed to be relevant. This is because the current non CEFR - aligned Form 5 English syllabus specifications promote students' creative thinking skill. The non CEFR-aligned Form 5

Ascertaining the Suitability of Writing Syllabus Specifications to the CEFR: Subject Matter Experts' Perspectives 
English syllabus specifications are also able to produce holistic individuals and able to help students to speak well. The findings also imply that components of English syllabus and assessment which are still relevant to be used shall help the Ministry of Education make the right decisions whether to make necessary modifications to the syllabus or go for a total revamp, particularly the writing syllabus.

\section{References}

Council of Europe. (2001). The Common European Framework of Reference for languages: Learning, teaching, assessment. Retrieved from http://www.coe.int/t/dg4/linguistic/cadre1_en.asp

Council of Europe. (2009). Relating language examinations to the Common European Framework of Reference for languages. Learning, teaching, assessment. CEFR: A manual. Strasbourg: Language Policy Division, Council of Europe.

Council of Europe. (2018). Common European Framework of Reference for languages: Learning, teaching, assessment. Companion volume with new descriptors. Retrieved from https://rm.coe.int/cefr-companion-volume-withnew-descriptors-2018/1680787989

Engku Haliza Engku Ibrahim, Isarji Sarudin, Khairiah Othman, Faridah Abdul Malik, \& Ainon Jariah Muhammad. (2017). The assessment of writing within the CEFR scale: A Malaysian context. Advanced Science Letters Journal, 5(3), 4944-4947. http://doi.org/10.1166/asl.2017.8986

Nurul Farehah Mohamad Uri \& Mohd Sallehhudin Abd Aziz. (2019). Teachers' evaluation of the suitability of reading syllabus specifications to the CEFR. Journal of English Language Teaching and Applied Linguistics, 1(1), 32-44. Retrieved from https://www.jeltal.org/wp-content/uploads/2019/12/ Teachers\%E2\%80\%99-Evaluation-of-The-Suitability-of-Reading-Syllabus-Specifications-to-The-CEFR.pdf

O'Dwyer, F. (2014). Towards critical, constructive assessments of CEFR-based language teaching in Japan and beyond. Osaka University Knowledge Archive. 31(3). $191-204 . \quad$ Retrieved from https://ir.library.osakau.ac.jp/repo/ouka/all/51427/slc_41-191.pdf

Taber, K. S. (2018). The use of Cronbach's Alpha when developing and reporting research instruments in Science Education. Research in Science Education Journal, 1 -24. http://doi.org/10.1007/s11165-016-9602-2

Wu, J. R. W. \& Wu, R. Y. F. (2012). GEPT and English language teaching and testing in Taiwan. Language Assessment Quarterly Journal, 9(1), 11-25. http://doi.org/10.1080/15434303.2011.553251

Zhao, W., Wang, B., Coniam, D., \& Xie, B. (2017). Calibrating the CEFR against the China Standard of English for College English vocabulary education in China. Language Testing in Asia Journal, 7(5). http://doi.org/10.1186/s40468-0170036-1

Zheng, Y., Zhang, Y \& Yan, Y. (2016). Investigating the practice of The Common European Framework of Reference for Languages (CEFR) outside Europe: a case study on the assessment of writing in English in China. ELT Research

Ascertaining the Suitability of Writing Syllabus Specifications to the CEFR: Subject Matter Experts' Perspectives 
Papers, 16 (1), 3 -19. Retrieved from https://eprints.soton.ac.uk/393651/1/ BC\%2520ELTRA\%2520article\%2520Apr\%25202016.pdf

Zhou, S \& Zhang, W. (2017). Exploring the adaptability of the CEFR in the construction of a writing ability scale for test for English majors. Language Testing in Asia, 7(18), 2 - 16. http://doi.org/10.1186/s.40468-017-0050-3 